\title{
Research on Marketing Strategy of Self-owned Brand Automobiles
}

\section{Qi Chen}

\author{
Chang'an University Xinghua College, Xi’an, Shaanxi, 710077
}

Keywords: marketing strategy; self-owned brand automobiles; industry development

\begin{abstract}
Facing the huge competitive pressures of domestic and foreign markets, how to accurately locate products, broaden marketing channels, enrich sales tools and enhance the influence of China's own brand vehicles through marketing strategies is the top priority for China's independent automobile industry. Therefore, it is necessary to improve the development strategy of China's self-owned brand automobile market. To improve the development strategy of China's self-owned brand automobile market, it is necessary to improve product quality and cultivate customer loyalty; give play to price advantage and improve service quality; broaden marketing channels and effectively integrate promotion strategies.
\end{abstract}

\section{Introduction}

An independent brand is the exclusive right of the company to own the product brand it produces. It is a carrier of comprehensive capital and traits of enterprise capital, technology, management and culture. It is the carrier for the creation and accumulation of core competitiveness of enterprises, and also an external manifestation of corporate value. China's auto brand itself refers to the fact that its products are developed by domestic enterprises and have complete intellectual property rights. Self-owned brands are the concentrated carrier and external manifestation of independent innovation of automobile enterprises. Whether the innovation results of enterprises are accepted by the market and the external value of enterprise products is recognized by the market. The market's recognition of its own brand products depends to a large extent on the company's marketing strategy.

\section{Status of China's Self-owned Brand Automobile Market}

Self-owned brand refers to the brand ownership of the products produced by the company, which is an important manifestation of the core competitiveness of the enterprise, and also the result of the company's development capability and complete intellectual property rights. The higher the market recognition of self-owned brand products, the higher the degree of innovation that represents the innovation of the enterprise. In this case, the marketing strategy of the enterprise plays an important role in improving brand awareness. At present, the production layout and product series of China's automobile industry have basically taken shape. In addition to the large-scale state-owned enterprises such as FAW Group and SAIC Group, which also form group size, it also includes private enterprise brands such as Chery, BYD, Great Wall and Geely. China's first self-owned brand car was produced by the first automobile manufacturer in 1958, called "Dongfeng". In 1959, the first self-owned brand premium sedan named "Red Flag” was born. However, due to the insufficient attention of the state to the self-owned brand automobile industry at that time, and after the reform and opening up, many foreign automobile brands entered China, and the market share of China's own brand cars fell to less than $10 \%$. At present, many world auto industry giants are stationed in China, but they only bring China into the ranks of the world's automobile production and consumption countries. In fact, China is not really among the world's automobile manufacturing countries. The strength of China's own brand cars is still very strong.

After the reform and opening up, many private enterprises have entered the wave of China's automobile industry development. Up to now, they have occupied more than half of China's own-brand cars. At the same time, the export volume of self-owned brands produced by private 
enterprises has surpassed that of state-owned enterprises. It can be said that private enterprises produce The self-owned brand car is the main force of China's current automobile export. However, the export strategy of China's own-brand cars is not based on technological advantages, but long-term marketing with low-cost strategies. The prices sold in European and American countries are generally lower than those produced in other countries. This is due to the fact that China has a large amount of cheap raw materials and labor, which reduces the production cost of automotive products. On the other hand, since many automobile-related parts produced in China have already occupied a major market share in the world market, this also helps. Save the production cost of China's auto products.

\section{Existing Problems in China's Self-owned Brand Automobile Marketing}

Take Chery Automobile Company, a typical automobile industry in China, as an example. The main goal of this enterprise is to manufacture national cars, but some models such as A3 have high market positioning and vehicle size defects. The manufacture of A3 undoubtedly embodies Chery's years of hard work, but it has problems such as no sunroof and narrow rear space. Compared with foreign advanced auto companies, the other party pays more attention to improving internal grades and increasing comfort, so it is more like Chery. A3 can better meet the requirements of mass consumption, so the marketing prospects are broader.

Marketing is undoubtedly a profound and profound course. It must have the corresponding skills, especially to be able to grasp the marketing environment. Although some brands have implemented a large number of promotional activities before entering the market, and the publicity effect has been good, many consumers are even willing to delay the purchase time. However, if the product launch time lacks rationality, such as the launch of products during the peak period of automobile sales, it will inevitably lead to the problem of unsatisfactory marketing results due to the fierce promotion and promotion of foreign independent brand cars.

Similarly, Chery A3 is an example. Although the market positioning of this model is its advantage, it is also a disadvantage. The so-called advantage lies in Chery's positioning in the mid-to-high-end market. Compared with foreign countries, the price advantage is very obvious, even slightly better than foreign brands. Compared with domestic independent brands, the price is obviously higher, from consumers. The reaction to a slight disappointment at its price conference is not difficult to see, higher than the actual consumption power of consumers. Coupled with the financial crisis, it has no advantage of competing with foreign brands, so it is forced to lower the selling price, which has an impact on the company's credibility and image.

\section{4P Strategy of China's Self-owned Brand Automobiles}

The establishment of brand image is a long-term accumulation process, not just the result of short-term market innovation and marketing. The quality of the product is the most important factor in the brand value. For the car, safety and reliability are its most basic quality requirements, and good after-sales service is also an indispensable part of product quality. Enterprises must be rationally positioned according to their own conditions. In the process of actively carrying out market innovation, strict quality assurance must be adopted as a premise, and they cannot be eager for success. For China's national auto companies with weaker strength, medium and low-end cars, especially economic cars, are better positioned at the beginning of their growth. At the same time, the brand series does not have to be spread too wide, and the models do not have to be launched too fast. The reasons are as follows: First, economic cars require lower technical capabilities, manufacturing levels, and capital costs, which are more suitable for the existing conditions of the country, so that domestic enterprises have the strength to provide low-end but high-quality products to the market and establish a good brand. Image. Different grades have different customer groups, and once the quality is wrong, the impact on the brand is comprehensive and far-reaching, which is difficult to compensate for any marketing means and market innovation. Second, economic cars are suitable for the current income and demand of Chinese nationals. They are the main demand targets 
for car popularization in developing countries, and they have huge and continuous market innovation space. Choosing to produce such products as a starting point is conducive to the rapid realization of economies of scale and the accumulation of comprehensive strength of national auto companies, thus moving towards a broader market and higher grades. Third, increasingly rational economic car demanders pay more attention to cost performance and practicability, are more sensitive to price response, and do not pay much attention to changes in models. Therefore, national enterprises with limited resources should be able to withstand loneliness and focus on continuously reducing product costs and improving product quality without having to put too much capital and technology on the types and personalities of products. In fact, even in the automotive market where competition is fierce, new models and new brands are emerging, a high-quality, low-cost, well-designed and economical Volkswagen car can remain popular for decades. For example, the German Volkswagen Beetle was born before the Second World War and has grown healthily for 70 years. It is still produced in Europe and America, with a total output of more than 20 million, the highest in the world. The Camry sedan has been selling well in the European and American Volkswagen car market since 1980. Today, more than 20 years later, it is still popular among customers. It ranks in the forefront of the world's best-selling cars; GM Chevrolet-Inpana as General Motors Volkswagen from 1958 Born in the year, it lasted for more than 40 years and remained active in the market until the 1990s.

China's auto brand has a short creation time. In the field of autos in the past 100 years, it is a newborn. Its brand must be built with a high cost performance as an entry point to gradually establish an image. Good cost performance is the fundamental guarantee for independent brands to enter the market and enhance value. In recent years, Chery and Geely have successfully entered the domestic and international markets where foreign brands have gathered. This is the strategy. When Toyota and Hyundai entered the international market and successfully achieved market innovation, creating a good brand image was also the main means. Not only the mid-to-low-end car market, but also the strategy of the high-end car market. The Toyota Lexus, which was launched in 1999, was initially squeezed into the high-end products of the long-established and brand-name products such as Mercedes-Benz and BMW at a price $30 \%$ cheaper than the same type of car. The car market gradually allows the market to accept and recognize its products and brands.

The terminal of the marketing channel is the customer. Therefore, establishing a good marketing channel not only helps to expand the market and market innovation, but also has a great impetus to shape the product brand. Therefore, channel construction has become an important task for the national automobile enterprise. At present, there are four main types of marketing channels for automobiles in China: one is a brand franchise store; the other is a car trading market in various places; the third is a car franchise chain store; the fourth is a mixed-brand car business point, such as a car supermarket. Among them, 4S brand franchise stores have become a popular and popular channel model because they enable consumers to easily access information and receive services, enabling auto companies to understand market dynamics and consumer needs more deeply and accurately, and provide good after-sales service. .

Although the independent brand is young and relatively weak, as a national brand, it still has a very special significance in the minds of the people. Therefore, from the government to the enterprise, and even from all walks of life, we must attach great importance to the promotion of self-owned brands, let the citizens better understand their own brand products, and understand the strength of their own brands for the national automobile industry, which is important for national welfare and national interests. Sex. Forming a national enterprise to launch more and better products, the nationals actively support the virtuous cycle of purchasing self-owned brand cars. As a government, it is not only necessary to publicize and support its own brands in many aspects, but also as an important consumer, it should also lead by example, purchase its own brand as an official vehicle, and even stipulate the minimum proportion of self-owned brands in different grades of official vehicles. The brand has actively cultivated domestic brands from domestic brands. As a company, we should create value for consumers and meet the needs of consumers in the first place, give full play to the advantages of national enterprises, and strive to develop high-quality products 
suitable for national needs, while making good use of their cultural consistency with consumers. And the national identity, carry out promotional activities, so that a good brand image is deeply rooted in the hearts of the people. Advertising is a very important means of publicity in the automotive industry. Among the global advertising costs, car advertising ranks first. In general, the advertising of new companies must adhere to a unified brand image, which includes the meaning of both the specific advertising appeal and the unified advertising style. Due to the special sales of automobiles, it is usually necessary for the promotion personnel to introduce the consumers one-to-one in detail. Enterprises must pay attention to the selection and training of the promotion personnel, especially the sales outlets set by the manufacturers, because the image and attitude of the promotion personnel are also Part of the quality of the product.

\section{Conclusion}

With the rapid development of science and technology, independent innovation is undoubtedly a hot issue of concern to all countries in the world, and it has created a broad space for development in China's own brand automobile market. At present, China's own-brand auto companies must reasonably analyze their current situation, firmly grasp relevant opportunities and policies, and formulate scientific and rational marketing strategies, such as strictly controlling product quality, optimizing sales positioning, etc., and minimizing the impact of international brand cars. Strike, only in this way, in the ever-changing and increasingly fierce competition in the auto market, China's self-owned brand auto companies can occupy a favorable position and thus achieve more healthy and sustainable development.

\section{References}

[1] Li Gang. Research on marketing strategy of China's own brand cars [J]. Shanghai Automotive, 2009 (06): 41.

[2] You Haiying, Hu Wei. Look at brand management from the similarities and differences of automobile sales models between China and Europe [J]. Value Engineering, 2004 (01): 79 - 80.

[3] Wang Juan. Analysis of the international marketing strategy of China's own brand cars [J]. Shanghai Automotive, 2007 (7)

[4] Wu Yong. Discussion on Automobile Culture Marketing in China [J]. Transportation and Transportation, 2007(4). 